RELATION BETWEEN VISCOSITY AND CHEMICAL CONSTITUTION. 1815

\title{
CLXXIX.-The Relation between Viscosity and Chemical Constitution. Part II. The Existence of Racemic Compounds in the Liquid State.
}

\section{By Arbert Ernest Dunstan and Ferdinand Bernard Thole.}

THE marked delicacy of the viscosimetric method renders it extremely probable that valuable information is to be obtained by its application to such problems as that indicated in the title. Of only one previous communication can it be fairly said that a definite answer has been given to the question as to the existence of racemic compounds in solution. Stewart (Trans., 1907, 91, 1537), by the determination of the absorption spectra of aqueous solutions of dextro-, meso-, and racemic tartaric acids, conclusively demonstrated that in the last case a curve was obtained which for low concentrations was identical with that afforded by the optically active forms, but at concentrations above 14 per cent. the curve for racemic acid diverged from that of the dextro-tartaric acid : this observation being indicative of the fact that, as the solution became more concentrated, the racemic form was more and more stable in the dissolved state, whereas at less concentrations than 14 per cent. an almost complete dissociation ensued, a conclusion in agreement with the statements of Raoult (Zeitsch. physikal. Chem., 1887, 1, 186), Ostwald (J. pr. Chem., 1885, [ii], 32, 341), and Marchlewski (Ber., 1892, 25, 1556).

Stewart (Stereochemistry, p. 41) points out that, with the abovementioned exception, there is no method available for the decision 
of this question, although Bruni and Padoa (loc. cit.) considered that from determinations of molecular weight they had obtained indications of the existence of complex molecules, whilst, on the other hand, Walden finds that racemates in solution have the same affinity constants as the optically active forms, and from vapour density determinations the same identity is discovered.

In a recent paper, Ranken and Taylor (Proc. Roy. Soc. Edin., 1907, 27,172 ), on investigating the physical properties of solutions containing independent optically active substances, point out that there is an unmistakable difference of properties between the optically active and the racemic solutions. This difference is most pronounced in the more concentrated solutions, and is no doubt an indication of the existence of racemic ions or molecules in solution. This conclusion is supported by the fact that in every case the viscosity of the racemic solution is less than that of the optically active form. This observation is of interest because the same authors show that some doubt exists as to the weight to be attached to density determinations, for whereas Perkin (Trans., 1887, 51, 362) gives the density of an 8.333 per cent. solution of the dextro-form at $15^{\circ} / 15^{\circ}$ as 1.03703 and of the racemic form at the same temperature and concentration as 1.03712, and Marchlewski gives for similarly comparable solutions of 14.018 per cent. as 1.06600 and 1.06623 resp ectively, Ranken and Taylor show that, on the average, the racemic solution has the less density, although it is fair to mention that these authors did not pursue their investigation from the point of view of density, a quantity which they only determined incidentally.

\section{EXPERIMENTAL.}

In the present communication, we have determined the viscosities and densities of dextro-, lævo-, meso-, and racemic tartaric acids at $25^{\circ}$ through a range of concentration in aqueous solution; dextroand racemic malic acids in aqueous solution; dextro-, lævo-, and racemic limonenes in the liquid state, and lævo- and racemic amyl alcohol in the liquid state.

The description of apparatus and method will be found in our previous papers (Trans., 1904, 85, 817 ; 1905, 87, 11 ; 1907, 91, 83 ; 1907, 91, 1728).

Most of the materials were specially prepared for us by Schuchardt and Kahlbaum, and were purchased with a grant from the Research Committee of this Society, to whom we make this grateful acknowledgment. We also desire to express our indebtedness to Dr. Stewart for the specimens of amyl alcohol and mesotartaric acid with which be supplied us. 
The Tartaric Acids.

\begin{tabular}{|c|c|c|c|}
\hline \multicolumn{4}{|c|}{ d-Tartaric Acid (Kahlbaum). M. p. $170^{\circ}$. } \\
\hline $\begin{array}{l}\text { Per cent. } \\
\text { tartaric acid. }\end{array}$ & $\begin{array}{c}\text { Time of } \\
\text { flow in seconds. }\end{array}$ & $\begin{array}{l}\text { Density, } \\
25^{\circ} / 4^{\circ}\end{array}$ & Viscosity. \\
\hline 0.0 & $737 \cdot 2$ & 0.9972 & 0.00891 * \\
\hline $4 \cdot 64$ & $799 \cdot 4$ & $1 \cdot 0181$ & 0.00991 \\
\hline $7 \cdot 99$ & $849 \cdot 7$ & 1.0337 & 0.01065 \\
\hline $11 \cdot 675$ & $922 \cdot 2$ & $1 \cdot 0511$ & 0.01175 \\
\hline $15 \cdot 01$ & $1000 \cdot 4$ & 1.0673 & 0.01294 \\
\hline 0.0 & $25 \cdot 2$ & 0.9972 & 0.00891 \\
\hline \multirow{2}{*}{\multicolumn{4}{|c|}{ * Thorpe and Rodger. }} \\
\hline & & & \\
\hline \multicolumn{4}{|c|}{ 1-Tartaric Acid (Kahlbaum). } \\
\hline $7 \cdot 69$ & $28 \cdot 6$ & $1 \cdot 0328$ & $0 \cdot 01047$ \\
\hline \multicolumn{4}{|c|}{ Mesotartaric Acid. } \\
\hline 0.0 & $282 \cdot 3$ & 0.9972 & 0.00891 \\
\hline $9 \cdot 966$ & $339 \cdot 9$ & $1 \cdot 0428$ & 0.01120 \\
\hline \multicolumn{4}{|c|}{ r-Tartaric Acid (Kahlbaum). M. p. $206^{\circ}$. } \\
\hline 0.0 & $737 \cdot 2$ & 0.9972 & 0.00891 \\
\hline $4 \cdot 02$ & $787 \bullet 2$ & $1 \cdot 0153$ & 0.00969 \\
\hline $7 \cdot 00$ & $833 \cdot 7$ & $1 \cdot 0290$ & 0.01040 \\
\hline $13 \cdot 14$ & $949 \cdot 3$ & $1 \cdot 0583$ & 0.01218 \\
\hline 0.0 & $282 \cdot 3$ & 0.9972 & 0.00891 \\
\hline $15 \cdot 98$ & $389 \cdot 4$ & $1 \cdot 0719$ & $0 \cdot 01319$ \\
\hline
\end{tabular}

The above results are plotted in Fig. 1, with the exception of that for the meso-acid, which falls near to the curve for the dextro-acid. The same viscometer has been used for each series of determinations to avoid errors arising from calibration. An examination of the figure will show that the curve for the racemic modification lies very uniformly below that of the active form, but it will be noticed that the differences are very small, comparable in fact with those of Ranken and Taylor. Were it not for the low solubility of the racemic acid, it would have been possible to push the observations to a greater concentration, and so probably obtain greater divergences from the curve for the dextro-acid.

The densities of the respective solutions show minute differences, but when plotted on a scale of sufficient size for reproduction, they are found to lie practically on a straight line. As mentioned in the introduction, a degree of accuracy much greater than is justifiable in the present case would be needed to show any marked differences between the racemic and active isomerides. 


\section{DUNSTAN AND THOLE: THE RELATION BETWEEN}

1-AmylMlcohol and the Racemic Modification Prepared from it by Distillation over Potassium Hydroxide. B. p. $129^{\circ}$.

$\begin{array}{ccc}\text { Time of flow. } & \text { Density, } 25^{\circ} / 4^{\circ} . & \text { Viscosity. } \\ 282.3 & 0.9972 & 0.00891 \\ 1733.0 & 0.8162 & 0.04476 \\ 1588.0 & 0.8188 & 0.4115\end{array}$

FIG. 1.

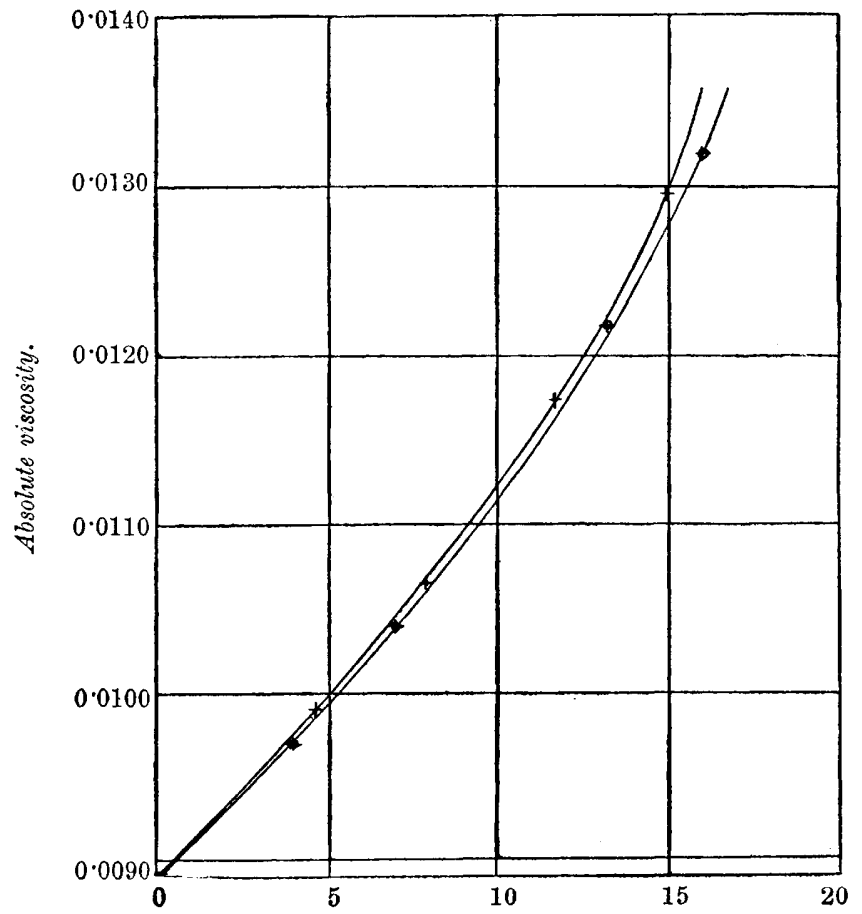

Concentration in grams per 100 grams of solution.

d-Tartaric acid (upper curve) and racemic acid (lower curve).

l- and d-Limonenes (Schuchardt), and the dl-Limonene prepared therefrom. B. p. $174 \cdot 5^{\circ}$.

Time of flow. Density, $25^{\circ} / 4^{\circ}$. Viscosity.

\begin{tabular}{|c|c|c|c|}
\hline 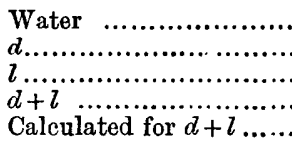 & $\begin{array}{l}282 \cdot 3 \\
344 \cdot 8 \\
649 \cdot 8 \\
448 \cdot 6\end{array}$ & $\begin{array}{l}0.9972 \\
0.8457 \\
0.8782 \\
0.8617 \\
-\end{array}$ & $\begin{array}{l}0.00891 \\
0.00923 \\
0.01806 \\
0.01223 \\
0.01365\end{array}$ \\
\hline
\end{tabular}

Although when one compares the densities and viscosities of the ndividual isomerides some doubt way be expressed as to their chemical 
purity, yet the fact that the viscosity of the $d+l$-form is less than the calculated mean value is indicative of the formation of a racemic compound.

We also examined specimens of the pinenes, prepared by Schuchardt, here, again, the $d$ - and $l$-forms had different viscosities, but the mean value calculated from these values and that determined for the $d+l$ form differed.

1- and d-Pinenes (Schuchardt). B. p.: dextro $=155^{\circ}$; lævo $=159^{\circ}$.

\begin{tabular}{|c|c|c|c|}
\hline & Time of flow. & Density, $25^{\circ} / 4^{\circ}$. & Viscosity. \\
\hline Water & $282 \cdot 3$ & 0.9972 & 0.00891 \\
\hline 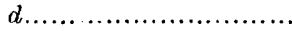 & $582 \cdot 6$ & 0.8711 & 0.01606 \\
\hline 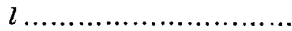 & $518 \cdot 0$ & $0 \cdot 8612$ & 0.01412 \\
\hline$d+l$ & $555 \cdot 2$ & 0.8668 & 0.01523 \\
\hline Calculated for $d+l$. & - & - & 0.01509 \\
\hline
\end{tabular}

d- and r-Malic Acids (Schuchardt). M. p.: $d=98-99^{\circ} ; r=128-129^{\circ}$.

$\begin{array}{cccc} & \text { Time of flow. } & \text { Density, } 25^{\circ} / 4^{\circ} . & \text { Viscosity. } \\ \text { Water } \ldots \ldots \ldots \ldots \ldots \ldots & 282.8 & 0.9972 & 0.00891 \\ d, 17.43 \text { per cent......... } & 460.1 & 1.0665 & 0.01550 \\ r, 17.43 \quad, \quad \ldots \ldots \ldots . & 395.6 & 1.0666 & 0.01333\end{array}$

The Viscosity of Sodium Ammonium Tartrate Solutions and the Determination of its Transition Point.

Early in the study of stereochemistry the observation was made that sodium ammonium tartrate and sodium ammonium racemate can only exist within definite temperature limits. When Pasteur neutralised racemic acid by equivalent quantities of sodium hydroxide and ammonia, he obtained, on crystallisation, equal amounts of the $d$ - and $l$-salts, whereas Staedel, under apparently similar conditions, obtained the sodium ammonium racemate.

Scacchi, in a comprehensive research, showed that at higher temperatures the racemate crystallised, but at lower temperatures the $d+l$-tartrates appeared. Wyrouboff further pointed out that $28^{\circ}$ was the transition point in question, and that the change involved the absorption or elimination of water, for if powdered sodium ammonium racemate is mixed with water below this temperature, it sets to a solid mass of the mixed $d$ - and $l$-tartrates, which apparently melts at $28^{\circ}$.

Van't Hoff (Bildung und Spaltung von Doppelsalzen, Leipzig, 1897) gives the methods of determining this transition point, namely: dilatometric (rising temperature), $26 \cdot 7-27 \cdot 7^{\circ}$; intersection of solubility curves, $27^{\circ}$; dilatometric (falling temperature), $29^{\circ}$.

To supplement the above work from another point of view, and with the expectation of adding yet another method of determining such transition points, we have measured the viscosities and densities 
1820 RELATION BETWEEN VISCOSITY AND CHEMICAL CONSTITUTION.

of aqueous solutions of sodium ammonium tartrate $(d l)$ at degree intervals from $25^{\circ}$ to $30^{\circ}$.

To avoid calibration errors of the viscometer, we have taken the product, time of flow $\times$ density, as being equivalent to viscosity.

FIG. 2.

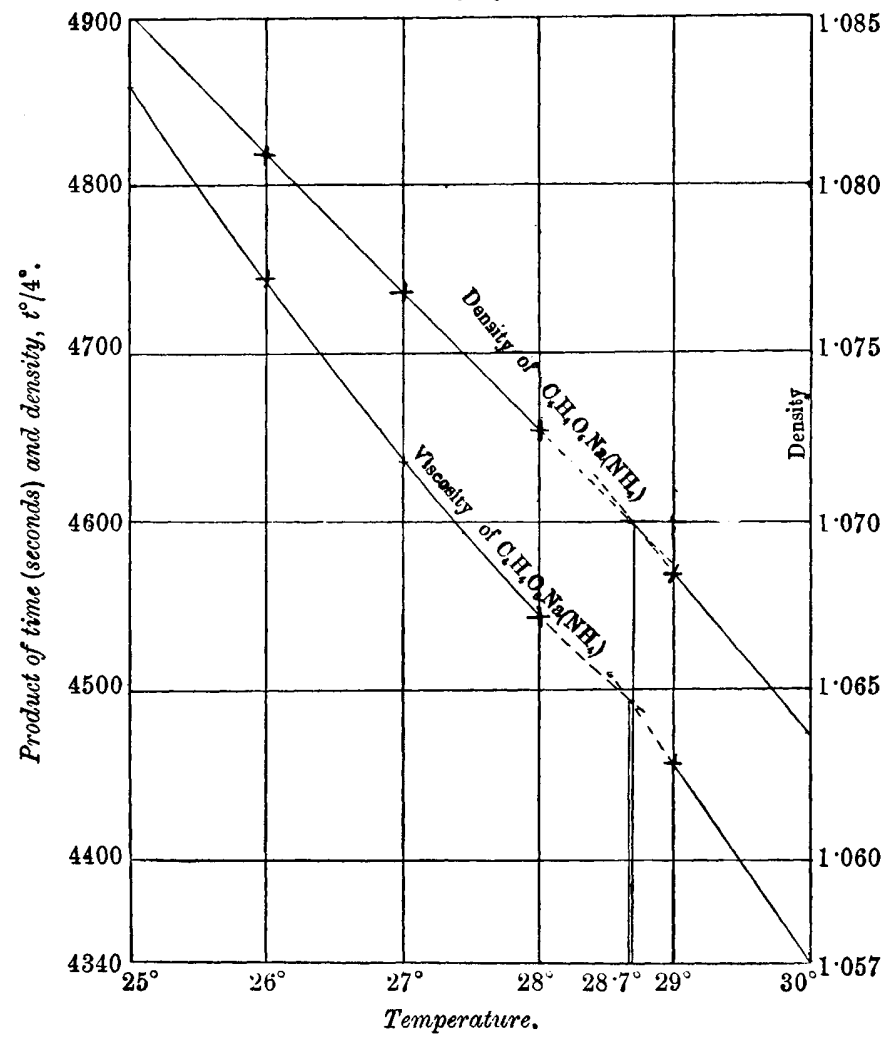

$V$ iscosity and density of sodium ammonium racemate and tartrate.

Sodium ammonium tartrate (Schuchardt) :

0.6934 lost $0.1959 \mathrm{H}_{2} \mathrm{O}$ at $110^{\circ}$. $\mathrm{H}_{2} \mathrm{O}=28.2$.

$\mathrm{C}_{4} \mathrm{H}_{8} \mathrm{O}_{6} \mathrm{NNa}, 4 \mathrm{H}_{2} \mathrm{O}$ requires $\mathrm{H}_{2} \mathrm{O}=28 \cdot 0$ per cent.

One hundred grams of solution contained $25 \cdot 19$ grams of the crystallised salt.

$\begin{array}{cccc}\text { Temp. } & \text { Time of flow. } & \text { Density. } & t \times d . \\ 25^{\circ} & 438 \cdot 3 & 1 \cdot 1085 & 485 \cdot 9 \\ 26 & 428 \cdot 2 & 1 \cdot 1081 & 474 \cdot 4 \\ 27 & 418 \cdot 4 & 1 \cdot 1077 & 464 \cdot 5 \\ 28 & 410 \cdot 3 & 1 \cdot 1072 & 454 \cdot 3 \\ 29 & 402 \cdot 6 & 1 \cdot 1068 & 445 \cdot 6 \\ 30 & 392 \cdot 3 & 1 \cdot 1064 & 434 \cdot 0\end{array}$


The above results are plotted in Fig. 2. It is to be noticed that each figure shows two curves intersecting at $28.7^{\circ}$ respectively for viscosity and density curves. The dotted parts of the curve were not, of course, determined, but serve to show the normal continuations of the full curves. It is probable that each curve shades into the other gradually from both sides of the transition point.

We intend to pursue this side of the work more completely in a further paper.

The following conclusions may be summarised :

I. The viscosities of $d$-and $l$-forms of tartaric acid are identical."?

II. Mesotartaric acid has a viscosity very close to that of the $d$ form.

III. Racemic compounds exist in solution, but at small concentrations dissociation takes place to a varying extent. It seems likely that the racemic compound has less residual affinity than the active forms; hence the increased viscosity due to the increased (doubled) molecular weight is more than balanced by the diminution due to a less degree of homogeneous or heterogeneous association.

On the other hand, it may of course happen that the formation of a more symmetrical molecular grouping favours mobility.

IV. The transition point between a racemate and its antipodes may be demonstrated by determining the viscosity through a range of temperature, when a change of curvature occurs at the transition point. The same point is also shown on the density curve, but to a less marked extent.

The authors desire to thank Assistant-Professor Smiles and Dr. Stewart for their suggestions and criticism.

Physical Chemical Laboratory, East Ham Technical College. 